\title{
Report
}

\section{Schneider Syndrome Managed Surgically or by Conservative Treatment}

\author{
Denlewende Sylvain Zabsonre ${ }^{1,}$, , Wendlassida Joelle Stéphanie Zabsonre Tiendrebeogo ${ }^{2}$, \\ Fulgence Kabore ${ }^{2}$, Abdoulaye Sanou ${ }^{1}$, Narcisse Damiba ${ }^{1}$, Yacouba Haro ${ }^{1}$, Ibrahim Dao ${ }^{1}$, \\ Alexandre Korsaga ${ }^{3}$, Sayouba Tinto ${ }^{3}$, Abel Kabre ${ }^{1}$ \\ ${ }^{1}$ Neurosurgery Department of Yalgado Ouedraogo Teaching Hospital, Joseph Ki-Zerbo University, Ouagadougou, Burkina Faso \\ ${ }^{2}$ Rheumatology Department of Bogodogo Teaching Hospital, Joseph Ki-Zerbo University, Ouagadougou, Burkina Faso \\ ${ }^{3}$ Orthopedics and Trauma Department of Yalgado Ouedraogo Teaching Hospital, Joseph Ki-Zerbo University, Ouagadougou, Burkina Faso
}

\section{Email address:}

szabsonre@gmail.com (D. S. Zabsonre), t_joelle@hotmail.com (W. J. S. Z. Tiendrebeogo), fulgencekabore@yahoo.fr (F. Kabore), sanou_abdou2002@yahoo.fr(A. Sanou),narcissedamiba5@gmail.com (N.Damiba),yaksterharo@gmail.com (Y. Haro), dao.ibrahim@gmail.com (I. Dao), korsalexs@yahoo.fr (A. Korsaga),drstinto@yahoo.fr (S. Tinto), kabrel@yahoo.fr (A. Kabre)

${ }^{*}$ Corresponding author

\section{To cite this article:}

Denlewende Sylvain Zabsonre, Wendlassida Joelle Stéphanie Zabsonre Tiendrebeogo, Fulgence Kabore, Abdoulaye Sanou, Narcisse Damiba, Yacouba Haro, Ibrahim Dao, Alexandre Korsaga, Sayouba Tinto, Abel Kabre. Schneider Syndrome Managed Surgically or by Conservative Treatment. International Journal of Neurosurgery. Vol. 4, No. 1, 2020, pp. 7-10. doi: 10.11648/j.ijn.20200401.12

Received: January 2, 2020; Accepted: January 27, 2020; Published: February 18, 2020

\begin{abstract}
Introduction. Schneider's syndrome is acute traumatic cervical central cord syndrome usually in stenotic cervical canal without other traumatic lesions. Early surgical management is controversial. The aim of this work was to study the treatment and evolution of cases of Schneider's syndrome in our department. Methods. It was a retrospective study run over 5 years Neurosurgery Department of Yalgado Ouedraogo Teaching Hospital. Results. Twenty-six (26) cases were included, all of them male. Average age was 53.69 years. Most frequent reasons of consultation were motor deficits of the 4 limbs (17 cases). On examination, the deficit predominated in thoracic limbs in 14 patients. There were 4 ASIA A, 5 ASIA B, 7 ASIA C and 10 ASIA D. Cervical traumas were mild or moderate in 22 cases. Cervical CT scan showed a narrowed cervical canal in all 24 cases where it was performed. MRI was done in 4 patients. It noted signs of spinal cord injury in all these cases. Ten patients were operated and 16 received conservative treatment. On leaving the hospital, 5 operated patients and 7 of those treated medically had partially recovered $(p=0.536)$. Conclusion. Schneider's syndrome most often occurred as a result of benign cervical trauma. There is no significant difference in the evolution of operated cases and those who had received conservative treatment. The therapeutic decision must be personalized and concerted.
\end{abstract}

Keywords: Schneider, Cervical Trauma, Cervical Central Cord Syndrome

\section{Introduction}

Schneider defined this syndrome in 1954 (J Neurosurg 11: $546-547,1954)$ as acute traumatic cervical central cord syndrome usually in stenotic cervical canal without other traumatic lesions (fracture/fracture dislocation/traumatic disc herniation/instability, hematoma). It manifests clinically in general by quadriplegia predominant most often in the upper limbs [1]. The evolution of this syndrome is most often unfavorable, especially in cases of complete quadriplegia in an elderly subject $[1,2]$. Therapeutically, opinions are divided between those who recommend early cervical decompression and those who propose conservative surgery $[3,4]$. The aim of this work was to study the evolution of Schneider's syndrome cases after surgical or conservative treatment in our department which is in a low-income country. 


\section{Methods}

It was a retrospective descriptive ant analytic study on the cases of Schneider syndrome treated in the neurosurgery department of Yalgado Ouedraogo University teaching Hospital from January 1, 2011 to December 31, 2015 (5 years). This study concerned all cases of cervical spine trauma with a neurological deficit admitted in the department during the study period (96 cases). Were included the cases where medical imagery of the cervical spine showed signs of cervical canal stenosis by degenerative phenomena without traumatic lesions (31 cases or $32.3 \%$ ). Cases where the medical record was not usable were excluded (5 cases). Fisher's test allowed us to compare qualitative variables with a $95 \%$ confidence interval. Any probability value (p) less than 0.05 was considered statistically significant.

\section{Results}

\subsection{Epidemiology}

Twenty-six cases were included in the study, all of them male. The average age was 53.69 years. The extremes were 33 and 72 years. The 41 to 50 and 51 to 60 age groups represented 6 cases and 12 cases respectively. Socio-professional status included cultivators / breeders (9 cases), office workers (6 cases); retirees (6 cases), workers in the informal sector (3 cases), manual workers (2 cases). The etiology of the trauma was an accident on the public road (13 cases), a fall ( 8 cases), a sudden movement of the head ( 3 cases), assault and injuries (1 case), lifting of a load ( 1 case). The trauma was mild in 10 cases, moderate in 12 cases and violent in 04 cases (associated with fractures of other organs). The delay between the trauma and the first consultation in neurosurgery was less than 1 day in 15 patients; from 3 to 10 days in 4 patients and more than 4 weeks in 07 other patients.

\subsection{Clinical Data}

The reason of consultation was represented by relative functional disorder of the 4 limbs (17 cases) or the upper limbs (2 cases); neck pain (11 cases); scalp excoriations (8 cases); hypoesthesia of the 4 limbs (1 case) and sphincter disorders (6 cases). Examination found a motor deficit in all patients. This deficit concerned only pelvic limbs in 3 patients (overall muscle strength was rated $3 / 5$ for the 2 limbs in 2 patients; it was $1 / 5$ on the left and $0 / 5$ on the right for the third patient); only thoracic limbs in 5 patients (overall muscle strength at 4 / 5 in the 2 limbs in 4 patients and $2 / 5$ in the fifth patient); the four limbs in 18 patients. In these 18 patients, overall muscular strength was rated $0 / 5$ for the 4 limbs in 9 patients. It was $1 / 5$ in thoracic limbs and $2 / 5$ in pelvic limbs in 5 patients; $3 / 5$ in thoracic limbs and $4 / 5$ in pelvic limbs in the other 4 . The onset of plegia (muscle strength less than 3/5) was immediately in 20 cases and progressive in 6 cases. Hypoesthesia was found in 5 patients; anesthesia in 4 patients; sphincter disorder in 8 patients. In short, the deficit predominated in the thoracic limb in 14 patients. There were 4 American Spine Injuries Association (ASIA) A, 5 ASIA B, 7 ASIA C and 10 ASIA D patients.

\subsection{Medical Imaging}

Standard radiography was performed in two patients and a CT scan in 24 cases. Four patients performed an MRI, 2 after a standard X-ray and the other 2 after CT scan. Radiographs showed osteoarthritis with disc pinches; CT scan narrowing of the canal by degenerative phenomena (osteoarthritis, disc protrusions and ligament enlargement). In all cases, MRI showed signs of spinal cord injury (T2 sequence intramedullary hyperintensity) on a narrowed cervical canal. The narrowing concerned the $\mathrm{C} 3$ to $\mathrm{C} 6$ vertebrae in all cases but it was more pronounced in $\mathrm{C} 5$ and $\mathrm{C} 6$ in 12 cases each, $\mathrm{C} 4$ in 9 cases, $\mathrm{C} 7$ in 7 cases and $\mathrm{C} 3$ in 3 cases. Figure 1 shows on $\mathrm{CT}$ and MRI images a cervical canal stenosis with spinal cord injury.

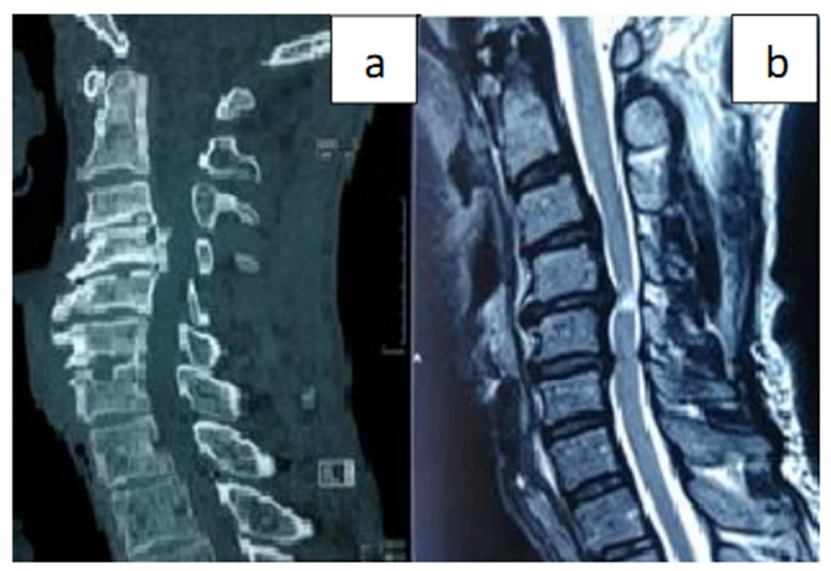

Figure 1. (a) CT of the cervical spine, in sagittal reconstruction, bone window showing the cervical canal stenosis from $C 3$ to $C 6$ by degenerative lesions (disc pinching, moderate body compaction with osteophytes and geodes). (b) MRI of the cervical spine, in a sagittal section, T2-weighted sequence showing the cervical canal stenosis from C3 to C6 and a hyper signal up to C4-C5.

\subsection{Treatment and Evolution}

Methylprednisolone was administered to all patients at 120 or $240 \mathrm{mg} /$ day for an average duration of 5.3 days with extremes of 3 and 7 days. kinesitherapy and analgesics were prescribed to all patients. Enoxaparin- was administered to 8 patients. A decompressive C3 C6 laminectomy was performed in 10 patients. This surgery took place around 8 days after their trauma for 7 patients; 1 month for 1 patient and 5 months for 2 patients.

Average hospital stay was 19.3 days (ranges 13 and 34 days) in operated patients and 15 days (ranges 5 and 53 days) in non-operated patients. Intra hospital evolution was marked by a partial recovery of motor deficit in 12 patients (including 5 operated), a stationary neurological state in 14 patients (including 5 operated) with 2 cases of infectious complications and 1 death. There was no statistical difference between the neurological evolution of the operated patients and those who had received conservative treatment $(\mathrm{p}=$ 0.536). 
Evolution after discharge from hospital with an average follow-up of 3 months (ranges 1 and 4 months) noted 3 cases of complete recovery (including 1 operated); 9 partially recovered cases (including 2 operated); 1 case remained stationary and 1 case of complications (bedsores) among the operated cases. Four deaths were noted (all cases of conservative treatment) and 8 lost to follow up. At 6 months (ranges 5 and 8 months), 9 patients (including 3 operated) had mildly disabling sequelae (Karnosky scale between 80 and $100 \%$ ). One operated patient had moderately disabling consequences (Karnosky scale between 50 and 70\%). There were 04 deaths among the non-operated cases and 12 lost to follow up.

\section{Discussion}

Schneider's syndrome was uncommon and represented 9.2\% of all traumatic injuries to the spine [4]. We had an average frequency of 5.2 cases per year. Other authors noted 6.25 cases per year [1]. The average age noted in our study (53.69 years) was close to that noted by other authors: 56.1 years [1]; 58 years old [4]. The onset of Schneider syndrome around the age of 50 could be explained by the fact that at this age the degenerative lesions causing the narrowing of the spinal canal are frequent. This narrowing of the cervical canal makes the cervical cord vulnerable to minimal trauma. This could explain the fact that minimal trauma (falling from own height or from a small height, sudden and rapid movement of the head) were the most frequent in our series, as in and in the literature [2, 4-8]. Clinically, it predominated in our serie incomplete quadriplegia predominant in thoracic limbs as in most of the literature $[2,7,9]$. Complete deficits predominated in elderly patients (65-69 years) [9].

CT scans performed by almost all of patients in our serie had made it possible to exclude a traumatic osteo disco ligament lesion or a hematoma and to object a narrowing of the cervical canal by degenerative lesions. MRI had been done very little. It made it possible to objectify a narrowed cervical canal and signs of spinal cord injury (hyper signal intramedullary in T2 weighted sequence) without spine traumatic injury in all cases where it was performed. The low rate of MRI in our series could be explained by the low accessibility (geographic and financial) of MRI in our country. However, this examination allows better analysis of the spinal cord and to highlight its suffering. CT-MRI couple allows to formally retain the diagnosis of Schneider syndrome $[4,10]$. So in front of post-traumatic neurological signs, perform a CT scan first and in absence of traumatic lesions do the MRI. In our series in the absence of this CT-MRI couple in all cases, CT scan showing a narrowing of the canal (without traumatic lesions) associated with clinical signs of cervical spinal cord injury allowed us to retain the diagnosis of Schneider's syndrome.

The place of corticosteroid therapy in the management of spinal contusion is discussed in the literature [3, 5-7]. Authors [7] who found that it had a contribution recommended methylprednisolone started early ( 8 hours) after the trauma and at a very high dose $(30 \mathrm{mg} / \mathrm{kg}$ intravenously the first hour followed by $5 \mathrm{mg} / \mathrm{kg}$ / hour the remaining 23 hours). In our series, although the majority of patients benefited from corticosteroid therapy, these high doses were not always reached. This could be justified by the high cost of these drugs and the late treatment.

The benefit of surgery and the time taken to perform it compared to onset of trauma remains controversial. Regarding timing of surgery, some authors did not find a difference between early surgery and late surgery (more than 24 hours after the trauma to allow spinal cord edema to decrease under corticosteroids and reduce the risk of worsening of the spinal cord contusion intraoperatively) [11, 12]. Others, however, found early surgery (less than 24 hours after the trauma) more beneficial [13-15]. Some authors found surgery more beneficial than conservative treatment [11]. Most authors note that there is no difference between surgery and conservative treatment $[2,4,16]$. In our study there was no statistically significant difference in the clinical course of operated and non-operated patients. Surgical management or conservative treatment must be personalized [2]. Our surgical indications were stopped after the opinion of several neurosurgeons or the staff. The criteria that militated more in favor of a surgical indication were the severity of the cervical canal stenosis and incomplete motor deficit. The surgical reserve concerned patients with complete motor deficit. This could also explain why we saw more deaths among non-operated patients. Indeed, according to several authors, the prognosis would be poor in the event of a complete motor deficit, especially in patients aged over 60 years $[1,2,11,13,17]$.

\section{Conclusion}

Schneider's syndrome was a rare pathology which more affects the elderly male subject. Mild or moderate trauma was the most common occurrence. The diagnosis was based on the clinic (post-traumatic motor deficit of limbs) and the cervical CT scan (absence of osteo-disco-ligament traumatic lesions, narrowed the cervical canal) and sometimes supported by MRI (T2-weighted intra-medullary hyper signal, cervical canal stenosis). Surgical or conservative treatment was performed depending on the case. There was no statistically significant difference in the course of operated patients and those who received conservative treatment. The therapeutic decision must depend on the patient and be the subject of concertation between neurosurgeons.

\section{References}

[1] Lenehan B, Street J, O'Toole P, Siddiqui A, Poynton A. Central cord syndrome in Ireland: the effect of age on clinical outcome. Eur Spine J. 2009; 18: 1458-1463.

[2] Lamothe G, Muller F, Vital J-M, Goossens D, Barat M. Evolution of spinal cord injuries due to cervical canal stenosis without radiographic evidence of trauma (SCIWORET): A prospective study. Annals of Physical and Rehabilitation Medicine. 2011; 54: 213-224. 
[3] Bowers CA, Kundu B, Hawryluk GW. Methylprednisolone for acute spinal cord injury: an increasingly philosophical debate. Neural Regen Res. 2016; 11 (6): 882-5.

[4] Epstein NE and Hollingsworth R. Diagnosis and management of traumatic cervical central spinal cord injury: A review. Surgical Neurology International. 2015; 6 (4): 140-153.

[5] Mung'ayi V, Qureshi M and Bugo J. Life threatening spinal shock and complete neurological recovery following minor spinal cord trauma in a patient with pre-existing cervical canal stenosis: case report. East African Medical Journal. 2009; 86: 529-532.

[6] Meister R, Pasquier M, Clerc D, Carron PN. Choc neurogénique. Revue Médicale Suisse. 2014; 10: 1506-10.

[7] Quenum K, Coulibaly O, Arkha Y, Derraz S, El Ouahabi A, El Khamlichi A. Atteinte médullaire cervicale post-traumatique sans lésion osseuse du rachis chez l'adulte: analyse de neuf cas consécutifs. Neurochirurgie. 2011; 57: 46-50.

[8] Perennes M, Henaux PL, Seguin P. Un syndrome centromédullaire après une chute de sa hauteur. Ann. Fr. Med. Urgence. 2015; 5: 51-53.

[9] Arul K, Ge L, Ikpeze T, Baldwin A, Mesfin A. Traumatic spinal cord injuries in geriatric population: etiology, management, and complications. J Spine Surg 2019; 5 (1): 38-45.

[10] Perez R, Pablo M, Igor P, Javier C, Alfonso L. Cervical Spinal Cord Injury without Computed Tomography Evidence of Trauma in Adults: Magnetic Resonance Imaging Prognostic Factors Wor Neuro. 2017.99: P192-9.

[11] Dahdaleh NS, Lawton CD, Ahmadieh TYE, Nixon AT, Tecle
NEE, Oh S and Al. Evidence-based management of central cord syndrome. Neurosurg Focus. 2013; 35 (1): 1-7.

[12] Park MS, Moon SH, Lee HM, Kim TH, Oh JK, Suh BK and al. Delayed Surgical Intervention in Central Cord Syndrome with Cervical Stenosis. Global Spine Journal. 2015; 5: 69-72.

[13] Dvorak MF, Noonan VK, Fallah N, Fisher CG, Finkelstein J, Kwon BKet al. The influence of time from injury to surgery on motor recovery and length ofhospital stay in acute traumatic spinal cord injury: an observational Canadiancohort study. J Neurotrauma. 2015; 32 (9): 645-54.

[14] Fehlings MG, Tetreault LA, Wilson JR, Aarabi B, Anderson P, Arnold PM and al. A Clinical Practice Guideline for the Management of PatientsWith Acute Spinal Cord Injury and Central Cord Syndrome: Recommendations on the Timing (24 Hours Versus $>24$ Hours) of Decompressive Surgery. Global Spine Journal. 2017; 7 (3): 195-202.

[15] Divi SN, Schroeder GD, Mangan JJ, Tadley M, Ramey WL, Badhiwala JH and al. Management of Acute Traumatic CentralCord Syndrome: A Narrative Review. Global Spine Journal. 2019; 9: 89S-97S.

[16] Karthik Yelamarthy P K, Chhabra HS, Vaccaro A, Vishwakarma G, Kluger P, Nanda A and al. Management and prognosis of acute traumatic cervical central cord syndrome: systematic review and Spinal Cord Society-Spine Trauma Study Group position statement. European Spine Journal, doi.org/10.1007/s00586-019-06085-z.

[17] David W, Brodell BA, Amit J, John CE, Mesfin A. National Trends in the Management of Central Cord Syndrome; An Analysis of 16,134 patients. Spine J. 2015; 15 (3): 435-442. 